Supporting Information to:

\title{
Actein and a Fraction of Black Cohosh Potentiate Antiproliferative Effects of Chemotherapy Agents on Human Breast Cancer Cells
}

Linda Saxe Einbond ${ }^{1}$

Masahito Shimizu ${ }^{1}$

Paiboon Nuntanakorn ${ }^{2}$

Colette Seter ${ }^{1}$

Rong Cheng ${ }^{1}$

Bei Jiang ${ }^{1}$

Fredi Kronenberg ${ }^{1}$

Edward J. Kennelly ${ }^{2}$

I. Bernard Weinstein ${ }^{1}$

\section{Affiliation}

${ }^{1}$ Columbia University College of Physicians and Surgeons, New York, NY, USA

${ }^{2}$ Lehman College in the Graduate Center, The City University of New York, Bronx, NY, USA

\section{Correspondence}

Linda Saxe Einbond

The Herbert Irving Comprehensive Cancer Center

College of Physicians and Surgeons

Columbia University

HHSC-1509

701 W. $168^{\text {th }}$ Street

New York

NY 10032

USA

Phone: $+1-212-305-6924$

Fax: +1-212-305-6889

E-mail: 1e2012@columbia.edu 


\section{Equipment and Methods}

\section{HPLC}

HPLC analyses were carried out on a Waters 2695 Separations Module (Milford, MA, USA) equipped with a Waters 996 photodiode array detector and operated with Empower software.

\section{TLC analysis}

Fractions were tested for triterpene glycosides and phenylpropanoids on silica gel $60 \mathrm{~F}_{254}$ plates (0.25 mm layer thickness) and RP18 $\mathrm{F}_{254}$ plates (1 mm layer thickness) from EM Science (Darmstadt, Germany). The solvent system for the silica gel TLC was chloroform-MeOH (9:1) and for the RP18 plates it was $\mathrm{MeOH}-\mathrm{H}_{2} \mathrm{O}$ (9:1). After development, the compounds were visualized under UV and by spraying with $1 \%$ vanillin in $10 \%(\mathrm{v} / \mathrm{v})$ hydrogen sulfate in ethanol.

\section{Preparation of the EtOAc extract}

Ground roots and rhizomes of black cohosh $(200 \mathrm{~g})$ were extracted with $80 \% \mathrm{MeOH} / \mathrm{H}_{2} \mathrm{O}(800$ $\mathrm{mL}$ ) overnight, filtered and evaporated under vacuum to remove $\mathrm{MeOH}$. The percent triterpene glycosides in the $\mathrm{MeOH}$ extract determined by HPLC-PDA were as follows: actein plus 23-epi26-deoxyactein (actein and 23-epi-26-deoxyactein overlapped), 3.0\%; cimiracemoside C, 1.1\%; cimigenoside: $1.0 \%$. Based on phenolic standards, phenolic compounds in the $\mathrm{MeOH}$ extract determined by HPLC-PDA were: fukinolic acid: 1.9\%, isoferulic acid, 0.64\% and ferulic acid: $0.17 \%$. According to Pure World Botanicals, it is hard to determine the rest of the components in black cohosh extract. Generally, most plant extracts, including black cohosh, contain resin, monosaccharides/oligosaccharides/polysaccharides, protein, amino acids, tannins, pigments, fat, wax, and inorganic constituents.

The resulting $\mathrm{H}_{2} \mathrm{O}$ portion was sequentially partitioned with hexane and EtOAc to yield three fractions: hexane, EtOAc and $\mathrm{H}_{2} \mathrm{O}$ [1]. Hexane was used to extract the non-polar phytochemicals and then ethyl acetate and $\mathrm{H}_{2} \mathrm{O}$ were used to extract the mid-polar and polar phytochemicals, respectively. The three resulting portions, hexane, EtOAc and $\mathrm{H}_{2} \mathrm{O}$ were evaporated under vacuum to yield $0.05 \%$ of hexane, $0.73 \%$ of EtOAc and $1.69 \% \mathrm{w} / \mathrm{w}$ of $\mathrm{H}_{2} \mathrm{O}$ extract. 


\section{HPLC Analysis of the Total Amount of Triterpene Glycosides and Polyphenols in the EtOAc Fraction of Black Cohosh}

\section{Triterpene glycosides}

To determine the total amount of triterpene glycosides in the EtOAc fraction of black cohosh we used an Agilent Hypersil column ODS $(4.0 \times 125 \mathrm{~mm})$ and the chromatogram was recorded at $203 \mathrm{~nm}$. The solvent system was a step gradient starting with $5 \%(\mathrm{v} / \mathrm{v})$ acetonitrile (solvent A) in $\mathrm{H}_{2} \mathrm{O}$ (B) and increasing to $75 \%$ acetonitrile over $55 \mathrm{~min}$. The gradient profile was: $0-18 \mathrm{~min}: 5$ $-28 \%$ A; $18-36 \min : 28-35 \%$ A; $36-45 \min : 35-55 \%$ A; $45-55 \min : 55-75 \%$ A. HPLC analysis indicated that actein accounted for about $2.5 \%$ of the total material in the EtOAc extract (Figure 1).

\section{Polyphenols}

An EtOAc fraction $(2.3 \mathrm{mg}$ ) of a black cohosh extract was dissolved with $1.5 \mathrm{~mL} \mathrm{70 \%} \mathrm{MeOH-}$ $\mathrm{H}_{2} \mathrm{O}$, and the resulting solution was sonicated for 30 seconds and filtered via a $0.45 \mu \mathrm{m}$ membrane filter.

Separations were carried out on a Phenomenex Aqua $\mathrm{C}_{18}$ column $(4.6 \times 250 \mathrm{~mm}, 5 \mu \mathrm{m}$ at ambient temperature with a flow rate of $1.0 \mathrm{~mL} / \mathrm{min}$ ). The sample volume injected was $10 \mu \mathrm{L}$, and data were analyzed at $320 \mathrm{~nm}$. The solvent system for the analysis of the phenolic constituents was composed of acetonitrile (A) and 10\% aqueous formic acid (B) using a step gradient elution of $5-15 \% \mathrm{~A}$ at $0-15 \mathrm{~min}, 15 \% \mathrm{~A}$ at $15-20 \mathrm{~min}, 15-50 \% \mathrm{~A}$ at $20-50 \mathrm{~min}$, and $50-100 \% \mathrm{~A}$ at $50-55 \mathrm{~min}$ (Figure 2).

Caffeic acid and ferulic acid were obtained from Sigma Chemical Co. (St Louis, MO). Isoferulic acid (97.37\% purity) was isolated from black cohosh extract. According to spiking experiments, the three major peaks in the HPLC-PDA chromatogram of the sample were identified as caffeic acid, ferulic acid, and isoferulic acid.

The amounts of the three phenolic constituents in the sample were calculated based on three different standard curves which were obtained by the analysis of three standard compounds in the 
different concentrations (Figure 2). The phenolic constituents in the EtOAc fraction are primarily composed of three compounds, caffeic acid, ferulic acid, and isoferulic acid. The total amount of the three major phenolic constituents in the fraction is $2.54 \%$.

\section{Statistical analysis: black cohosh in combination with chemotherapy agents}

The aim of the statistical analysis was to determine whether combinations of actein or the EtOAc fraction, with chemotherapy agents, yielded statistically different results from the chemotherapy agents used alone when tested for growth inhibition on human breast cancer cells. A two-way analysis of variance (ANOVA) [2] was initially used to determine whether it was valid to compare individual treatments to each other. If the analysis indicated it was valid to continue, individual treatments were compared by use of the t-test.

A two-way ANOVA produced two values of interest: (1) the F-values (the ratio of two mean squares) for the two factors and the interaction between the two factors (actein/fraction and chemotherapy agent), and (2) a mean squared error (MSE), which is an estimate of the experimental error derived from the entire set of data. For paclitaxel plus actein: ANOVA shows that the ability of each drug to kill cells is statistically significant. The respective $p$ values were: actein, $1.0 \times 10^{-18}$; paclitaxel, $1.3 \times 10^{-27}$; actein/paclitaxel interaction, $1.5 \times 10^{-14}$.

The LSD t-test indicated that under the fixed paclitaxel concentrations 0 and $0.25 \mathrm{nM}$, there were very significant differences $(\mathrm{p}<0.01)$ among the four different actein concentrations. Under the paclitaxel concentration $1 \mathrm{nM}$, there were very significant differences between the actein concentrations 0.1 and $1 \mu \mathrm{g} / \mathrm{mL}$. For paclitaxel $1 \mathrm{nM}$, the respective $\mathrm{p}$ values for the combination of increasing actein concentrations were as follows: $0.1 \mu \mathrm{g} / \mathrm{mL}, \mathrm{p}=0.26 ; 1 \mu \mathrm{g} / \mathrm{mL}, \mathrm{p}=0.002 ; 10$ $\mu \mathrm{g} / \mathrm{ml}, \mathrm{p}=2 \times 10^{-8}$. 


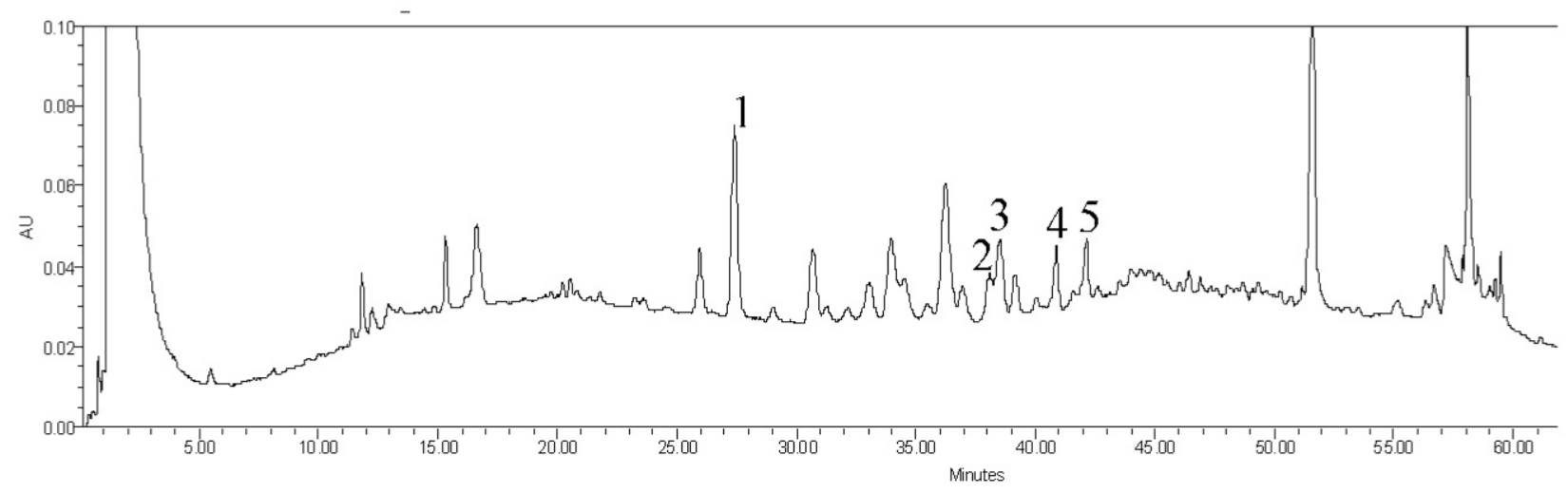

HPLC-PDA chromatogram of the EtOAc fraction

$\begin{array}{clr}\text { Peak } & \text { Triterpene glycosides } & \text { EtOAc } \\ \text { 1. } & \text { Cimiracemoside F } & 2.4 \\ \text { 2. } & \text { Actein } & 2.5 \\ \text { 3. } & \text { 23-Epi-26- Deoxyactein } & 4.7 \\ \text { 4. } & \text { Unknown triterpene glycoside } & 2.3 \\ \text { 5. } & \text { Unknown triterpene glycoside } & 2.1\end{array}$

Total

13.9

Figure 1. HPLC analysis of the percent triterpene glycosides in the ethyl acetate (EtOAc) fraction of black cohosh. 


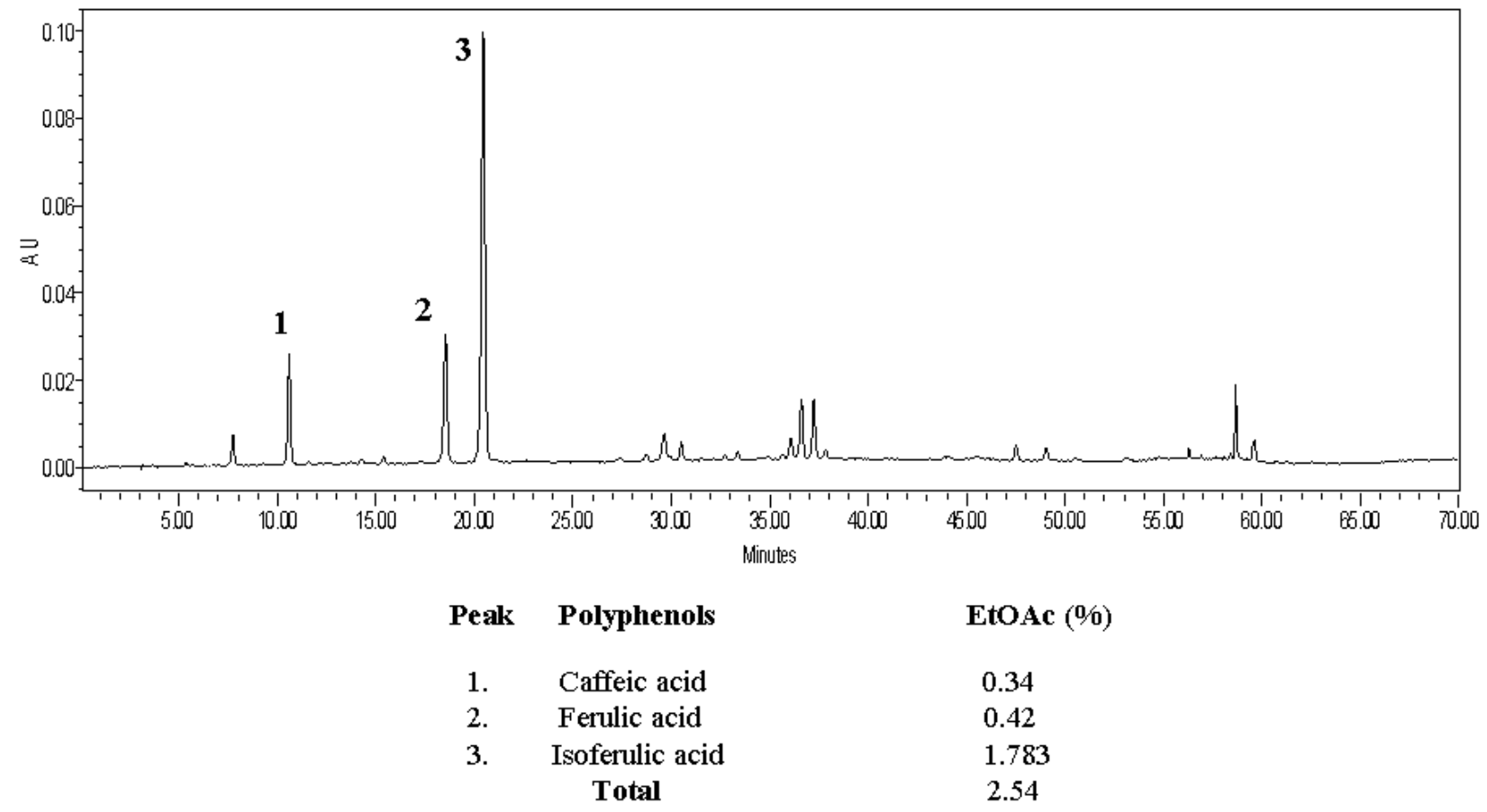

Figure 2. HPLC analysis of the percent polyphenols in the ethyl acetate (EtOAc) fraction of black cohosh

\section{References}

${ }^{1}$ Kennelly EJ, Gerhauser C, Song LL et al. Induction of quinone reductase by withanolides isolated from Physalis philadelphica (tomatillos). J Agric Food Chem 1997; 45: 3771-7

${ }^{2}$ Zar JH. Biostatistical Analysis. Upper Saddle River: Prentice Hall; 1999. Section 18.4 